\title{
Visual Impairment and its Rehabilitation: A Review
}

\author{
Raju kaiti ${ }^{1 *}$, Ranjila Shyangbo ${ }^{2}$, Shruti Singh ${ }^{2}$ and Chanda Pandey ${ }^{2}$ \\ ${ }^{1}$ Consultant Optometrist, M Optom, Nepal Eye Hospital \\ ${ }^{2}$ Optometry Student, 3rd year, National Academy of Medical Sciences
}

*Corresponding author: Raju Kaiti, M Optom, Consultant Optometrist, Nepal Eye Hospital, Nepal, India

\begin{abstract}
Visual impairment (VI) is a condition of reduced visual performance that cannot be remedied by refractive correction (spectacles or contact lenses), surgery or medical methods. Visual Impairment is a broader term that encompasses both Low vision and Blindness. The prevalence of visual impairment is estimated to be around 2.2 billion in the world as per World Health Organization (WHO). Causes of Visual Impairment differs significantly in different regions. Saying that, still cataract and refractive errors are main causes of visual impairment globally. Owing to its negative impact on the individual's dailies, professional life, productive time, confidence, and self-respect, VI needs to be addressed timely and appropriately. Visual impairments do have profound consequences for the individual, however effective rehabilitation services can restore independence and therefore ameliorate these consequences and restore the individual's quality of life.
\end{abstract}

Keywords: Visual Impairment; Blindness; low Vision; Rehabilitation; Optical Devices; Non-Optical Devices

\section{Introduction}

Impairment of any kind (sensorial or motor) is a bane for any human being. With visual impairment being one of the leading causes of sensorial impairment, it is necessary to acknowledge its prevalence, causes and methods to avoid them, if possible. Also, at the same time, it is important to understand that the term "visual impairment", "blindness" and "Low vision" are not synonymous; rather visual impairment includes low vision as well as blindness. Simply, Visual impairment (VI) is a condition of reduced visual performance that cannot be remedied by refractive correction (spectacles or contact lenses), surgery or medical methods [1]. Various definitions of visual impairment have been given by various concerned authorities. International Statistical Classification of Diseases and Related Health Problems (ICD) defines visual impairment categories primarily on the basis of recommendations made by a World Health Organization (WHO) Study Group in 1972 [2] and defines as:

- low vision is defined as visual acuity of less than $6 / 18$, but equal to or better than $3 / 60$, or a corresponding visual field loss to less than 20 degrees in the better eye with best possible correction
- blindness is defined as visual acuity of less than $3 / 60$, or a corresponding visual field loss to less than 10 degrees in the better eye with best possible correction.

Since, the ICD definition of visual impairment is based on best corrected visual acuity (BCVA), which exclude uncorrected refractive error as a cause of visual impairment, leading to substantial underestimation of the total visual impairment burden by about 38\%, Lalit Dandona [3] and colleagues debated a revision in these definitions and defined:

- a person with low vision as one who has impairment of visual functioning even after treatment and/or refractive correction, and has a visual acuity of less than $6 / 18$ to light perception, or a visual field of less than $10^{\circ}$ from the point of fixation, but who uses, or is potentially able to use, vision for the planning and/or execution of a task [4].

- blindness is defined as visual acuity of less than $6 / 60$, equivalent to central visual field of $20^{\circ}[5,6]$.

- A guideline has been instated to define "Legal Blindness" by Social Security Act to help people receive government 
assistance, such as Social Security disability benefits. Legal

Blindness is defined as:

Remaining vision in the better eye after best correction is $20 / 200(6 / 60)$ or less OR contraction of the peripheral visual fields in the better eye (A) to 10 degrees or less from the point of fixation; or (B) so the widest diameter subtends an angle no greater than 20 degrees [7].

Some other definitions and types of blindness adopted by different countries and institutions are:

\section{Avoidable Blindness}

It is the blindness that could be either treated or prevented by known, cost effective means. It can either be preventable or curable. It includes:

- $\quad$ Cataract

- Glaucoma

- Diabetic retinopathy

- $\quad$ Corneal infections

- Ocular trauma

- $\quad$ Refractive error

\section{Curable Blindness}

It is the stage of blindness where the damage is reversible by prompt management. E.g.: Cataract

\section{Preventable Blindness}

It is the type of blindness in which the loss of vision that could have been completely prevented by effective preventive and prophylactic measures

Example: Xerophthalmia

\section{Manifest Blindness}

It restricts the accomplishment of tasks for daily living leading to impairment in mobility.

Vision less than 1/60 to just perception of light in the better eye with best correction is considered as manifest blindness

\section{Absolute Blindness}

It restricts the ability of even perceiving the light. E.g.: Optic atrophy.

\section{Economic Blindness}

It is the level of blindness that prevents an individual from earning his wages. Vision less than $6 / 60$ to $3 / 60$ in the better eye with best correction is considered as economic blindness

\section{Social Blindness}

It hampers an individual from socially interacting with the family and peer groups in a satisfactory manner. Vision less than $3 / 60$ to $1 / 60$ in the better eye with best correction is considered as social blindness.

\section{Classification:}

The classification of visual impairment varies worldwide [8]. Since ICD is considered the standard worldwide classification therefore, the ICD definitions of visual impairment are used most often for worldwide estimates of visual impairment. The ICD-11 classification of visual impairment (which specifies all levels of vision loss, for each eye, and is used for coding a visual impairment as the diagnosis) is listed in the table below [2] (Table 1):

Table 1:

\begin{tabular}{|c|c|c|}
\hline \multirow[b]{2}{*}{ Category } & \multicolumn{2}{|c|}{ Presenting distance visual acuity } \\
\hline & Worse than: & $\begin{array}{c}\text { Equal to or better } \\
\text { than: }\end{array}$ \\
\hline \multirow{3}{*}{$\begin{array}{l}0 \text { No vision } \\
\text { impairment }\end{array}$} & & 12-Jun \\
\hline & & $5 / 10(0.5)$ \\
\hline & & $20 / 40$ \\
\hline \multirow{3}{*}{$\begin{array}{l}1 \text { Mild vision } \\
\text { impairment }\end{array}$} & 12-Jun & 18-Jun \\
\hline & $5 / 10(0.5)$ & $3 / 10(0.3)$ \\
\hline & $20 / 40$ & $20 / 70$ \\
\hline \multirow{3}{*}{$\begin{array}{l}2 \text { Moderate vision } \\
\text { impairment }\end{array}$} & 18-Jun & Jun-60 \\
\hline & $3 / 10(0.3)$ & $1 / 10(0.1)$ \\
\hline & $20 / 70$ & $20 / 200$ \\
\hline \multirow{3}{*}{$\begin{array}{l}3 \text { Severe vision } \\
\text { impairment }\end{array}$} & Jun-60 & Mar-60 \\
\hline & $1 / 10(0.1)$ & $1 / 20(0.05)$ \\
\hline & $20 / 200$ & $20 / 400$ \\
\hline \multirow{2}{*}{4 Blindness } & Mar-60 & $1 / 60^{*}$ \\
\hline & $1 / 20(0.05)$ & $1 / 50(0.02)$ \\
\hline 6 Blindness & $\begin{array}{l}\text { 20/400 No light } \\
\text { perception }\end{array}$ & $\begin{array}{c}5 / 300(20 / 1200) \text { or } \\
\text { counts fingers }(\mathrm{CF}) \text { at } 1 \\
\text { meter }\end{array}$ \\
\hline \multirow{3}{*}{5 Blindness } & $1 / 60^{*}$ & \multirow{3}{*}{ Light perception } \\
\hline & $1 / 50(0.02)$ & \\
\hline & $5 / 300(20 / 1200)$ & \\
\hline 6 Blindness & No light perception & \\
\hline 9 & $\begin{array}{l}\text { Undetermined or } \\
\text { unspecified }\end{array}$ & \\
\hline \multirow[t]{2}{*}{ Category } & $\begin{array}{l}\text { Presenting near visual } \\
\text { acuity }\end{array}$ & \\
\hline & \multicolumn{2}{|c|}{ Worse than N6 or M 0.8 with existing correction } \\
\hline
\end{tabular}

In the above table, it should be noted that in the revision of the ICD-10 categories of visual impairment proposed in 2003 by a WHO consultation on the development of standards for characterization of vision loss, low vision is replaced by two categories: moderate visual impairment (presenting visual acuity less than 6/18 but equal 
to or better than 6/60) and severe visual impairment (presenting visual acuity less than $6 / 60$ but equal to or better than $3 / 60$ ) [9]. Also, the previous classifications of visual impairment considered visual acuity as the only determining factor for categorizing visual impairment; loss of function due to hemianopia, loss of contrast sensitivity, photophobia, visual distortion, diplopia, or visual perceptual difficulties were not considered. These factors have been addressed on ICD-10 and ICD-11. Vision impairment results as an involvement of more than one factor which may include visual acuity, visual field, and contrast sensitivity. Therefore, these are the most clinically useful quantifiers of visual impairment [8]

\section{Prevalence and Incidence:}

According to World Health Organization, globally, at least 2.2 billion people have a vision impairment or blindness, of whom at least 1 billion have a vision impairment that could have been prevented or has yet to be addressed [10], among whom 1 billion people includes those with moderate or severe distance vision impairment or blindness [10] However, with the introduction of the global initiative to eliminate avoidable blindness (vision 2020: the right to sight), many agree that the initiative is in the right direction to reduce the prevalence of avoidable blindness [11]. Estimates of the number of visually impaired persons vary, depending upon the criteria used [12]. In 2002, it was estimated that with bestcorrected vision there were 161 million individuals with VI globally [13]. However, when the prevalence of uncorrected refractive error was included, this value increased substantially to 314 million individuals with VI [14]. This implies that an additional 153 million individuals were visually impaired from uncorrected refractive error alone [14]. This statistics stress upon the underestimation of total visually impaired population if uncorrected refractive error is to be looked. Thus, the importance of correction and management of refractive error is significantly high for the management of visual impairment [15].

An interesting fact is that, the majority of the visually impaired population are among the elderly and shows female preponderance. The incidence of visual impairment increases with age; more than two-thirds of persons with low vision are over the age of 65 [16] The global prevalence of blindness is greater in women than in men [17], especially among high-income regions which may be attributed to longer life expectancies and lack of access to health care services especially in rural areas [18]. Visual impairment secondary to uncorrected refractive error starts at a younger age than cataract [19], therefore childhood blindness must not be undermined. Vision impairment, particularly among children interferes with most life experiences [20]. World Health Organization (WHO) estimates the number of blind children in the world to be approximately 1.4 million, out of which three quarter resides within developing and underdeveloped countries like Nepal.20 According to mid-term review of Nepal Blindness Survey
2010, an estimated 1,013,041 children less than 16 years of age (prevalence among under 16 age group assumed to be $10 \%$ based on different studies varying from 3 to $20 \%$ ); 1,164,053 persons between 16-35 years of age have uncorrected refractive error for distance (estimated prevalence 15\%) [21].

\section{Causes and Risk Factors:}

Not only the ocular morbidities, but also the systemic health conditions including trauma can pre-dispose a person to ocular abnormalities, rendering them visually impaired. The causes of visual impairment are numerous, including not only congenital and acquired ocular conditions, but systemic diseases with ocular complications and neurological insult and trauma. The major causes of visual impairment in vary widely from region to region, being largely determined by socioeconomic development, and the availability of primary health care and eye care services 20 The Vision 2020- Right to Sight has identified five priorities for elimination of preventable blindness and they are: Cataract, Trachoma, Onchocerciasis, Childhood blindness and Refractive errors and low vision services. However, the causes of visual impairment are largely determined by the economy of the country. Refractive error is one of the most common causes of visual impairment around the world and the second leading cause of treatable blindness 19 which remain as a common cause in both developed and developing countries. Globally, the leading causes of blindness and moderate and severe VI include uncorrected refractive error, cataract, and macular degeneration [22]. The major causes of blindness in developed and developing countries are shown in the table below (Table 2):

Table 2:

\begin{tabular}{|l|ll|}
\hline \multicolumn{1}{|c|}{ Developed Countries } & \multicolumn{2}{|l|}{ Developing Countries } \\
\hline & $\bullet$ & Cataract \\
- $50 \%$ of all blindness is due to Age related & - & Infectious disease \\
Macular Degeneration. & - & Xeropthalmia \\
- $10-20 \%$ is due to Glaucoma, Diabetic & - & Injuries \\
Retinopathy and Cataract. & - & Glaucoma \\
- Refractive error & - & Onchocerciasis \\
& - & Refractive Error \\
\hline
\end{tabular}

The incidence of these conditions increases with age. So, increasing age is the single- most risk factor for visual impairment. However, the causes of visual impairment among children are different from those of adults. Among children, the causes of vision impairment vary considerably across countries; for example, in developing countries congenital cataract is a leading cause, whereas in developed it is more likely to be retinopathy of prematurity, uncorrected refractive errors remain a common cause [20]. Though the global burden of childhood blindness is insignificant in comparison to that of adult, children have life time of blindness ahead. So, the proper cause and management should be instituted more readily among pediatric age groups. According 
to Nepal Blindness Survey (NBS), 1981 and Mid-term Review of NBS, 2010, the major causes of childhood blindness and the main avoidable causes in Nepal are:

- $\quad$ Cataract

- Glaucoma

- $\quad$ Retinopathy of prematurity is emerging in major cities

- $\quad$ Refractive errors

- Low vision, which encompasses visual impairment and blindness from untreatable causes

\section{Impact:}

Visual impairments are pervasive in their effect on the individual's entire life: social, occupational, recreational, and familial life. Blindness, of all chronic illnesses and disabilities, is the second leading cause of inability to work, with visual impairments being historically correlated with underemployment, unemployment, and poverty [23]. Recent studies have also suggested that sensory impairments, including visual impairment increase the risk for mortality, especially among the elderly. Vision loss can affect one's quality of life (QOL), independence, and mobility and has been linked to falls, injury, and worsening of mental health, cognition, social function, employment, and educational attainment. The economic impact of vision loss is also substantial. Individuals with VI experience more symptoms of depression than those without. The implications of childhood blindness and VI may be more significant because of greater life expectancies [10].

\section{Rehabilitation:}

It has been reported that proper management of individuals with VI can provide the same quality of life as that of normally sighted individuals [24]. Therefore, rehabilitation should be made accessible to every visually impaired person. A visually impaired person needs following types of rehabilitation:

\section{Medical Rehabilitation:}

This includes early identification of the visually impaired people and timely management which can be either medical or surgical management. Medical rehabilitation not only includes correction of refractive error, but prevention of any predisposing factors like early cataract surgery, timely management of retinal and optic nerve disease to stop progression and preserve the residual useful vision, vitamin A supplements among children. Low Vision Aids form an important part of medical rehabilitation of visually impaired people so that they can benefit from their residual useful vision. They are of two types, optical \& non-optical.

1. Optical type: Spectacle magnifiers, Handheld and stand magnifiers, Microscopic lenses, Telescopic lenses, Projection devices etc.
2. Non-optical type: Large print books, Type writers, Typo scopes, Special illumination devices, Talking books etc.

\section{Educational Rehabilitation:}

Educational rehabilitation includes education avenues provided to the visually impaired in the residential blind schools with the facility of Braille system of education. Louis Braille's invention of Braille alphabet system in 1832 provided a tremendous impetus to the education of visually impaired children throughout the world. After gaining primary education from these schools, these children are placed in regular schools in the general education system. This system of education that is, first Braille from special blind school and then learning from general schools in the presence of regular teachers as well as a resource teacher is known as integrated system of education. It aims at normalizing the life and education of visually impaired children in the least restrictive environment along with sighted children in general schools.

\section{Vocational Rehabilitation:}

Vocational rehabilitation aims at helping the visually impaired earn their livelihood and live as useful citizens. They are taught simple occupations like candle making, chalk making, book binding, chair canning etc. Rehabilitation intervention can affect coping patterns over time and that direction and magnitude of such an effect may depend on the type of rehabilitation received.

\section{Psychosocial Rehabilitation:}

It includes mobility training, training for basic life skills and social support. Mobility training can be provided with cane or guide person or devices. Visually impaired needs to have a good and efficient training in the use of his remaining senses so that he acquires some amount of independence in his mobility. Basic survival skills should be taught. The social support extended by family and community is very important.

\section{Conclusion}

The burden of visual impairment is prevalent in every country, be it developing or developed. Visual impairments do have profound consequences for the individual, however effective rehabilitation services can restore independence and therefore ameliorate these consequences and restore the individual's quality of life. Therefore, proper counseling, timely referrals and appropriate low vision aids, trainings and rehabilitations are very important aspects of eye care and patient management.

\section{Conflict of Interest}

Nil

\section{References}

1. DeCarlo DK, Woo S, Woo GC (2006) Patients with low vision. In: Benjamin WJ, editor. Borish's clinical refraction. 2nd (Eds). Philadelphia: Elsevier pp. 1591-1618. 
2. (2019) World Health Organization: International Statistical Classification of Diseases and Related Health Problems. $10^{\text {th }}$ revision. Current version. Blindness and low vision.

3. Lalit Dandona, Rakhi Dandona (2006) Revision of visual impairment definitions in the International Statistical Classification of Diseases. BMC Medicine pp. 4: 7.

4. World Health Organization: The Management of Low Vision in ChildrenReport of a WHO Consultation, Bangkok (1992) pp. 23-24.

5. United Nations Development Programme: Human Development Reports 1990-2005 china.

6. Taylor HR, Livingston PM, Stanislavsky YL, McCarty CA (1997) Visual impairment in Australia: distance visual acuity, near vision, and visual field findings of the Melbourne Visual Impairment Project. Am J Ophthalmol 123(3): 328-337.

7. Social Security Act. United States Social Security Administration. Code of Federal Regulations, Title 20, Ch. III, Pt. 404, Subpt. P, App. 1. List of Impairments. U.S. DHHS (SSA). Washington, USA.

8. Leat SJ, Legge GE, Bullimore MA (1999) What is low vision? A reevaluation of definitions, Optom and Vis Science 76(4): 198-211.

9. Consultation on development of standards for characterization of vision loss and visual functioning. Geneva, 4-5 September 2003. Geneva: WHO (2003).

10. World Health Organization: Blindness and Visual Impairment. ( cited on 8th April 2020).

11. RRA Bourne, SR Flaxman, T Braithwaite (2017) Magnitude, temporal trends, and projections of the global prevalence of blindness and distance and near vision impairment: a systematic review and metaanalysis. The Lancet Global Health 5(9): e888-e897.

12. RW Massoff (2002) A model of the prevalence and incidence of low vision and blindness among adults in the US. Optom ans Vis Sci 79(1): 31-38.

13. S Resnikoff, D Pascolini, D Etya'ale (2004) Global data on visual impairment in the year 2002. Bull World Health Organ. 82(11): 844-551.
14.S Resnikoff, D Pascolini, SP Mariotti, GP Pokharel (2008) Global magnitude of visual impairment caused by uncorrected refractive errors in 2004. Bull World Health Organ 86(1): 63-70.

15. Raju Kaiti (2017) Uncorrected Refractive Error and Associated Childhood Visual Impairment-Any new steps for prevention? Ophthalmology and Vision Science 1(4): 167-170.

16. L Ringering, P Amaral (1988) The elderly low vision client: treatment issues. J Vision Rehabil 2(3): 53-60.

17. GA Stevens, RA White, SR Flaxman (2013) Global prevalence of vision impairment and blindness magnitude and temporal trends, 1990-2010. Ophthalmology. 120(12): 2377-2384

18. (2019) World Health Organization. Global initiative for the elimination of avoidable blindness-Action plan 2006-2011. Geneva: World Health Organization pp. 1-18.

19. Dandona L (2001) Blindness in the Indian state of Andhra Pradesh. Invest Ophthalmol Vis Sci 42(5): 908-916.

20. Ranjila Shyangbo, Raju Kaiti (2020) Importance of Vision Screening in Children of Developing Countries Like Nepal. EC Ophthalmology 11(4): 54-56

21. Kaiti R, Pradhan A, Dahal HN, Shrestha P (2018) Pattern and Prevalence of Refractive Error and Secondary Visual Impairment in Patients Attending a Tertiary Hospital in Dhulikhel, Nepal. Kathmandu Univ Med J 62(2):114-119.

22. Pascolini D, Mariotti SP (2012) Global estimates of visual impairment: 2010. Br J Ophthalmol 96(5): 614-618.

23. Veterans Health Initiative: Blindness and Visual Impairmen. Department of V Eterans A ffairs Veterans Health Administration Washington DC 20420.

24. Kavitha V, Manumali MS, Praveen K, Heralgi MM (2015) Low vision aid-A ray of hope for irreversible visual loss in the pediatric age group. Taiwan J Ophthalmol 5(2): 63-67.

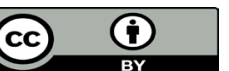

This work is licensed under Creative

Commons Attribution 4.0 License

To Submit Your Article Click Here:

Submit Article

DOI: $10.32474 /$ TOOAJ.2020.03.000152

\begin{tabular}{l}
$\begin{array}{c}\text { Trends in Ophthalmology } \\
\text { Open Access Journal }\end{array}$ \\
Assets of Publishing with us \\
- Global archiving of articles \\
- Immediate, unrestricted online access \\
- Rigorous Peer Review Process \\
\hline - Authors Retain Copyrights \\
\hline Open Access Journal
\end{tabular}

